\title{
Somatostatin prevents the postoperative increases in plasma amino acid clearance and urea synthesis after elective cholecystectomy
}

\author{
H Heindorff, P Billesbølle, S Ligård Pedersen, R Hansen, H Vilstrup
}

\begin{abstract}
The importance of glucagon on postoperative changes in hepatic amino-nitrogen conversion were investigated in six patients undergoing elective cholecystectomy for uncomplicated gall stones. Patients were given infusions of somatostatin (bolus of $6 \mu \mathrm{g} / \mathrm{kg}$ followed by continuous infusion of $6 \mu \mathrm{g} / \mathrm{kg} / \mathrm{h}$ ) from induction of anaesthesia to the end of investigation, the first postoperative day (30 hours). Controls were 16 patients undergoing the same procedures omitting the somatostatin infusion. In all patients blood concentration and plasma clearance of total $\alpha$-amino-nitrogen, and amino acid stimulated rate of urea synthesis were measured. Elective cholecystectomy decreased blood $\alpha$-amino-nitrogen concentration from mean (SEM) $2.9(0.2)$ to $2.4(0.1) \mathrm{mmol} / \mathrm{l}(\mathrm{p}<0.05)$, increased the clearance of total $\alpha$-amino-nitrogen from $5 \cdot 2(0.3)$ to $6.6(0 \cdot 3) \mathrm{ml} / \mathrm{s}(p<0 \cdot 05)$, and increased the rate of amino acid stimulated urea synthesis from 27 (1) to 37 (2) $\mu \mathrm{mol} / \mathrm{s} \quad(p<0.05)$ pointing to increased hepatic removal of amino-nitrogen at expense of plasma amino-nitrogen. Infusion of somatostatin prevented increase of glucagon for 24 hours after surgery, and prevented the negative changes in postoperative nitrogen homeostasis resulting from the postoperative changes in hepatic nitrogen conversion, suggesting glucagon as mediator. The exact mechanism remains in doubt, however, because of the multiple effects of somatostatin.
\end{abstract}

(Gut 1995; 36: 766-770)

Keywords: somatostatin, urea synthesis, cholecystectomy, amino acid clearance.

Copenhagen, Denmark $\mathrm{H}$ Heindorff

Department of Surgery D, Gentofte County Hospital, Denmark

P Billesbølle

$S$ Ligård Pedersen

R Hansen

Department of Medicine V, Århus University Hospital, Århus, Denmark H Vilstrup

Correspondence to: Dr H Heindorff, Department of Gastrointestinal Surgery C-2121 Rigshospitalet, 9 Blegdamsuej, DK-2100 Copenhagen, Denmark.

Accepted for publication 12 September 1994

Regulation of postoperative loss of body protein is not fully understood. The liver plays a primary part in the catabolic stress response after surgery. The hepatic effectiveness of conversion of plasma amino-nitrogen into urea nitrogen increases considerably (more than tissue amino-nitrogen release), so that the plasma amino-nitrogen decreases because of the depletion by the liver. ${ }^{12}$ This phenomenon is a consistent response to cholecystectomy.

Many possible regulators has been proposed. ${ }^{3-8}$ The 'traditional' catabolic hormones (glucagon, cortisol, and catecholamines) are established mediators.
Both glucagon and cortisol stimulate urea synthesis, ${ }^{9-11}$ and combined hormonal-neural blockade of these hormones returned postoperative changes in hepatic amino-nitrogen conversion to normal values. ${ }^{12}$ The aim of this study was to investigate the effect of glucagon on these changes by determination of aminonitrogen clearance and urea synthesis during infusion of somatostatin.

\section{Methods}

\section{Patients}

The experimental group comprised six patients (one male and five females) with uncomplicated gall bladder stones verified by ultrasonography. Their average age was 42 years (range 23-58) and body weight $67 \mathrm{~kg}$ (range 62-98). Controls were 16 patients (6 males and 10 females) reported previously ${ }^{12}$ with an average age of 42 years (range 34-59) and body weight of $77 \mathrm{~kg}$ (range 55-92). None of the patients had any other known disease. There was no difference in the duration in the surgical procedure or maximum postoperative temperature between the two groups.

The subjects gave their informed consent, and the protocol was in accordance with the declaration of Helsinki II and was approved by the local committee of ethics.

\section{Surgical procedures}

The patients were sedated with benzodiazepine (Apozepam) 5-10 $\mathrm{mg}$ and anaesthetised with low dose fentanyl-droperidol and $\mathrm{N}_{2} \mathrm{O}_{2}$. Cholecystectomy was performed by a laparotomy through a subcostal incision. The intra and postoperative course was uncomplicated in all cases, and without exploration of the common bile duct. No blood transfusion was given.

\section{Protocol}

Each subject was their own control. They were investigated twice on the day before surgery after a nine hour fast with free access to tap water, and on the first postoperative day 26 hours after skin incision. Each investigation consisted of a prime continuous infusion into an antecubital vein ${ }^{1}$ of a mixture of amino acids (Pfrimmer, Erlangen, Germany), measured to be free from urea and ammonia. This established a steady state both with respect to blood amino acid concentration and hepatic amino-nitrogen conversion as assessed 
TABLE I Concentrations of total $\alpha$-amino-nitrogen ( $A A N$ mmoll) and glucose (mmolll) before and after cholecystectomy in both groups fasting and during amino acid infusion

\begin{tabular}{|c|c|c|c|c|}
\hline & \multicolumn{2}{|l|}{ Before } & \multicolumn{2}{|c|}{ First postoperative day } \\
\hline & Fasting & AA load & Fasting & AA load \\
\hline \multicolumn{5}{|l|}{$\mathrm{AAN}(\mathrm{mmol} / \mathrm{l})$} \\
\hline $\begin{array}{l}\text { Control } \\
\text { Somatostatin }\end{array}$ & $\begin{array}{l}2.9(0.2) \star q \\
2.5(0.3) \pm 9\end{array}$ & $\begin{array}{l}5.0(0.2)+1 \\
4.6(0.5)\end{array}$ & $\begin{array}{l}2 \cdot 4(0 \cdot 1) \star q \\
4 \cdot 1(0 \cdot 5) \pm 1\end{array}$ & $\begin{array}{l}3.9(0.3) \neq 9 \\
5.8(0.5)\end{array}$ \\
\hline \multicolumn{5}{|l|}{ Glucose $(\mathrm{mmol} / \mathrm{l})$} \\
\hline $\begin{array}{l}\text { Control } \\
\text { Somatostatin }\end{array}$ & $\begin{array}{l}4 \cdot 6(0 \cdot 1) \ddagger \\
5 \cdot 1(0 \cdot 1) \ddagger\end{array}$ & $\begin{array}{l}4 \cdot 8(0 \cdot 1) \$ \\
5 \cdot 5(0 \cdot 1) \$\end{array}$ & $\begin{array}{l}5.7(0.3) \ddagger \\
6.5(0.4) \neq 9\end{array}$ & $\begin{array}{l}5 \cdot 6(0.3) \int_{9} \\
7 \cdot 1(0.6) 59\end{array}$ \\
\hline
\end{tabular}

$\star, \dagger$ :Significant decrease before $v$ after fasting and AA load; $\ddagger$, $\S$ : significant increase before $v$ after fasting and AA load; $\uparrow$ : significant increase during AA infusion. Data presented as mean (SEM).

\section{Calculations}

Elimination of infused amino-nitrogen was quantified by the plasma clearance $(\mathrm{ml} / \mathrm{s})$, calculated as infusion rate divided by average plasma concentration during steady state.

The urea nitrogen synthesis rate (UNSR) $(\mu \mathrm{mol} / \mathrm{s})$ was calculated as urinary excretion rate of urea (E) corrected for accumulation of urea (A) in the total body water and fractional gut hydrolysis (L):

$$
\mathrm{UNSR}=(\mathrm{E}+\mathrm{A}) /(1-\mathrm{L})
$$

The total body water (TBW) was estimated from body weight (BW, $\mathrm{kg})$, body height $(\mathrm{BH}$, $\mathrm{cm})$, and age (Y, years), by the formulas ${ }^{19}$ :

the rate of urea synthesis. The priming sisted of an infusion of amino-nitrogen at a rate of $41.2 \mu \mathrm{mol} \mathrm{min}{ }^{-1} \mathrm{~kg}^{-1}$ body weight for 60 minutes, and the continuous infusion of an infusion for 180 minutes at a constant rate of $22.3 \mu \mathrm{mol} \mathrm{min}^{-1} \mathrm{~kg}^{-1}$ body weight. ${ }^{1}$ The amino acid infusion resulted in a total fluid volume of $500 \mathrm{ml}$.

Venous blood samples were drawn from the contralateral arm before start of the amino acid infusion and then every half hour.

Urine was collected quantitatively by voiding from the time when the amino acid infusion was started and every hour during infusion.

After the preoperative investigation, patients had free access to tap water and received for the rest of the day a diet containing $2000 \mathrm{kcal}$ and $75 \mathrm{~g}$ of protein. On the day of operation the patients received $2000 \mathrm{ml}$ of isotonic saline intravenously, and on average $2500 \mathrm{ml}$ of isotonic saline during the operation.

During the amino acid infusions no other infusion was given.

The patients in the experimental group received, in addition, a hormonal blockade started during induction of anaesthesia and maintained until the end of investigation - that is, for 30 hours after skin incision. Both groups received morphine intramuscularly, $10 \mathrm{mg}$ every six to eight hours for relief of pain.

\section{Blockade}

Natural somatostatin (SS28) (DuraScan Medical Products A/S, Denmark) was given as a bolus injection of $6 \mu \mathrm{g} / \mathrm{kg}^{-1}$ followed by a continuous infusion of $6 \mu \mathrm{g} / \mathrm{kg} / \mathrm{h}$ dissolved in isotonic saline.

There was no undesirable effect of the blockade concerning change in blood pressure, heart rate, or blood glucose.

\section{Analyses}

Total $\alpha$-amino-nitrogen concentration in plasma and urine was determined by the dinitroflourobenzene method ${ }^{13}$ (coefficient of variation of analysis $1.25 \%$ ) and urea in blood and urine by the Urease-Berthelot method ${ }^{14}$ (coefficient of variation $1 \%$ ). Blood glucose concentration ${ }^{15}$ was determined by a glucose oxidase method.

Plasma insulin and glucagon concentrations were determined by radioimmunoassay. ${ }^{16} 17$ Plasma cortisol concentration was determined by high pressure liquid chromatography. ${ }^{18}$
$\mathrm{TBW}=0 \cdot 3265 \mathrm{BW}+0 \cdot 2239 \mathrm{BH}-0 \cdot 138 \mathrm{Y}-14 \cdot 47$ for men and $\mathrm{TBW}=0 \cdot 2363 \mathrm{BW}+0 \cdot 1962 \mathrm{BH}-0 \cdot 0272 \mathrm{Y}-10 \cdot 26$ for women.

$\mathrm{L}$ was taken to be $17 \% .^{20}$

The nitrogen exchange during steady state was calculated as the percentage of infused amino-nitrogen appearing as urea nitrogen by excretion plus accumulation.

\section{Statistical analysis}

Values are given as mean (SEM). Difference between groups was evaluated by two tailed $t$ tests of means or pairs as appropriate. p Values smaller than 0.05 were considered statistically significant.
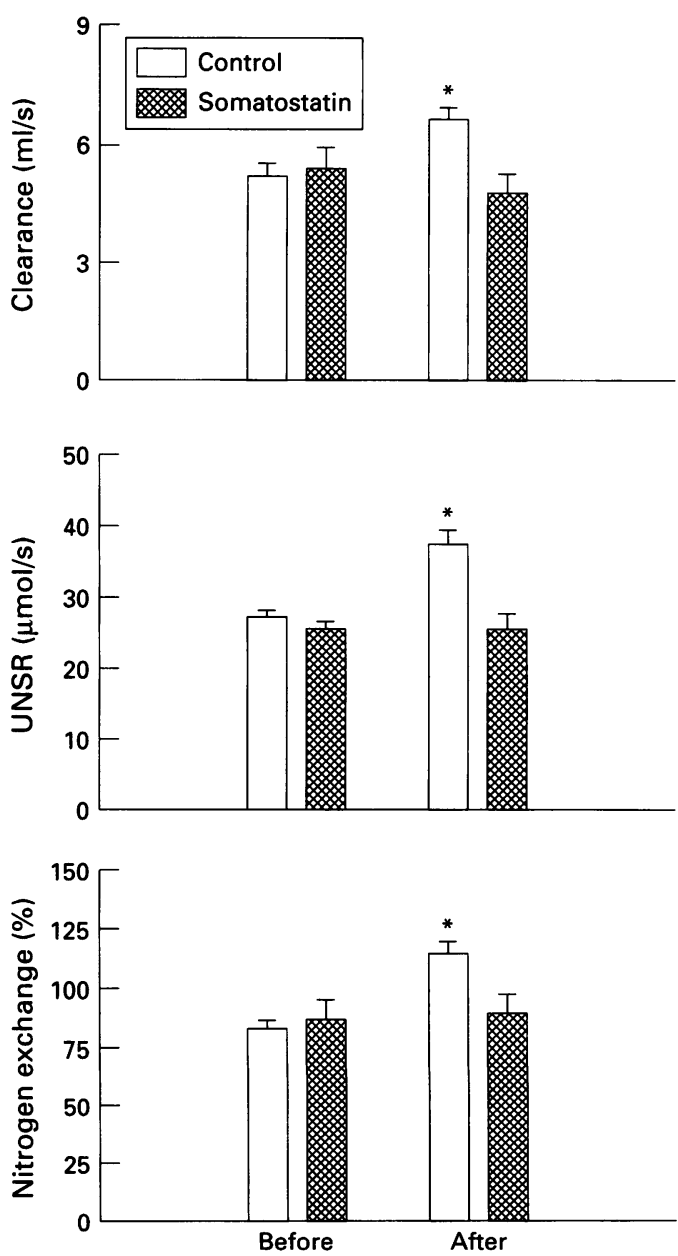

Figure 1: Total $\alpha$-amino-nitrogen clearance, rate of urea nitrogen synthesis rate (UNSR), and nitrogen exchange during amino acid infusion in the control group (open bars) and the somatostatin treated group (hatched bars) before and after the operation. *Significant increase $p<0.05)$. 


\section{Results}

\section{Amino-nitrogen}

The amino acid infusions increased the fasting plasma concentrations of total $\alpha$-aminonitrogen by about $80 \%$ (Table I). Postoperatively, the amino acid concentrations were about $20 \%$ lower in control patients $(p<0.05)$, and $60 \%$ (fasting) and $25 \%$ (amino acid load) higher in the patients with blockade $(p<0.01)$ (Table I).

Postoperatively, the plasma clearance of total $\alpha$-amino-nitrogen increased by about $25 \%$ in the control group $(p<0.05)$, and did not change in the blockade group (Fig 1).

\section{Urea synthesis}

In the control group, surgery increased the amino acid stimulated rate of urea synthesis by one third $(p<0.05)$. In the blockade group, surgery did not change the rate of urea synthesis (Fig 1).

Preoperatively, $15 \%$ of the infused aminonitrogen was retained in the body, and postoperatively in the control group $15 \%$ more was excreted than infused $(p<0 \cdot 02)$. The blockade prevented this postoperative loss of aminonitrogen (Fig 1).

\section{Glucose}

Surgery increased fasting blood glucose concentration by $25 \%(p<0.05)$ in the control group, without further increase during amino acid load (Table I). In the blockade group surgery increased the fasting concentration by $30 \%(\mathrm{p}<0.05)$, and the amino acid load increased it further by $10 \%$ (Table I).

\section{Hormones}

Glucagon - preoperatively, the amino acid infusion increased plasma glucagon concentration by about $40 \%$ over fasting in both groups $(p<0 \cdot 02)$. Postoperatively, glucagon more than doubled $(p<0.001)$ in the control group, while it remained unchanged in the blockade group (Table II). Postoperatively, the fasting value was $70 \%(\mathrm{p}<0.05)$ higher than preoperatively in the blockade group. Somatostatin halved glucagon concentration for 12 hours after start of operation (Fig 2) $(p<0.05)$,

TABLE II Plasma concentrations of glucagon ( $p g / m l)$, insulin $(\mu U / l)$, and cortisol (nmoll) before and after cholecystectomy in both groups fasting and during $A A$ infusion

\begin{tabular}{|c|c|c|c|c|}
\hline & \multicolumn{2}{|l|}{ Before } & \multicolumn{2}{|c|}{ First postoperative day } \\
\hline & Fasting & AA load & Fasting & AA load \\
\hline \multicolumn{5}{|l|}{ Glucagon (pg/ml) } \\
\hline Control & $92(6)^{\star}$ & $128(10)^{\star}$ & $107(9)^{\dagger}$ & $226(13)^{\dagger}$ \\
\hline \multicolumn{5}{|l|}{ Insulin $(\mu \mathrm{U} / \mathrm{l})$} \\
\hline Control & $15(2)$ & $15(2)$ & $19(2)^{\dagger}$ & $40(6)^{\dagger}$ \\
\hline Somatostatin & $11(1)$ & $14(1)$ & $16(2)$ & $17(2)$ \\
\hline \multicolumn{5}{|l|}{ Cortisol (mmol/l) } \\
\hline Control & $288(34)^{ \pm, 5}$ & $226(21)^{5}$ & $503(56)^{\ddagger}, 9$ & $399(57)^{9}$ \\
\hline Somatostatin & $348(57)$ & 443 (109) & $333(66)$ & $416(152)$ \\
\hline
\end{tabular}

${ }^{\star}+$ Significant increase during AA load before and postoperatively; $\ddagger$ significant increase of fasting values; $\$$ Isignificant decrease during AA load before and postoperatively. Data presented as mean (SEM).
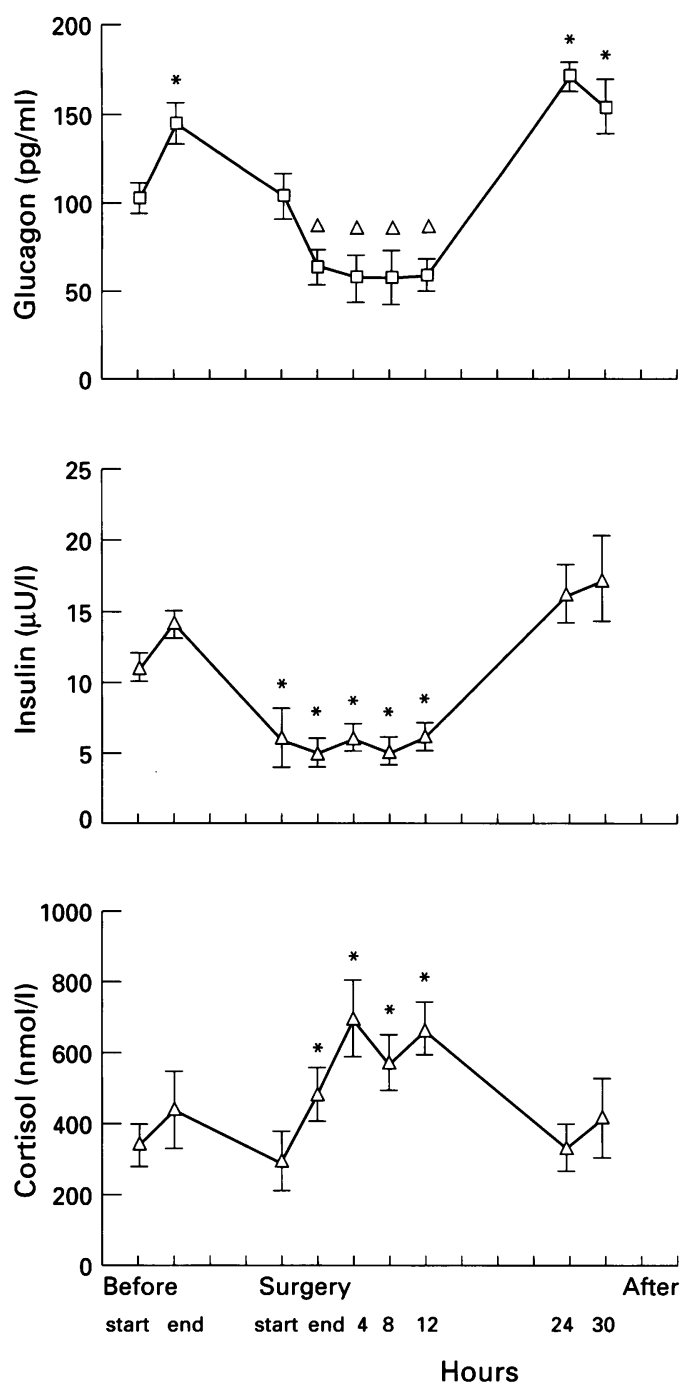

Figure 2: Plasma concentrations of glucagon (increase $\left({ }^{*}\right.$ ) and decrease $(\triangle), p<0.05)$, insulin (decrease $\left(^{*}\right)$, $p<0.05$ ), and cortisol (increase ( $\left.{ }^{\star}\right), p<0.05$ ) during the investigation period in the somatostatin treated patients.

whereafter the concentration rose to the preoperative value during amino acid load.

Insulin - preoperatively, the amino acid load did not change insulin in both groups, but doubled it after surgery $(\mathrm{p}<0.001)$ in controls, while it remained unchanged in the blockade group. In the blockade group insulin was halved $(p<0.05)$ for 12 hours after which it rose to preoperative values (Table II, Fig 2).

Cortisol - surgery increased fasting cortisol by $75 \%(p<0.05)$ and the amino acid load decreased it by $25 \%(p<0.05)$ postoperatively in controls. In the blockade group cortisol doubled from four to 12 hours after surgery, but was normal after 24 hours (Table II, Fig 2).

\section{Discussion}

Somatostatin prevented the hepatic catabolic response to cholecystectomy.

The increase in the control group of urea synthesis at lower amino acid concentration after surgery reflects changes in liver function with regard to amino-nitrogen disposal - that is, more urea was synthesised and more aminonitrogen was lost for protein synthesis. 
Postoperatively, glucagon, cortisol, and catecholamine concentrations increased. Glucagon directly increases the hepatic efficacy for urea synthesis, ${ }^{910}$ and cortisol increases the capacity of urea synthesis in rats ${ }^{11}$ and acts permissively for the effects of glucagon on urea synthesis. ${ }^{21}$ Catecholamines have no effect in themselves on urea synthesis ${ }^{22}$ but seem to act permissively for the effects of cortisol. ${ }^{23}$ Prostaglandins interact with the catabolic hormones and accelerates the hepatic catabolic response. ${ }^{24-26}$ Cytokines seem to accelerate hepatic synthesis of acute phase proteins ${ }^{27}$ and increase plasma glucagon and cortisol to concentrations as seen after stress. ${ }^{28} 29$ Other hormones such as human growth hormone $^{7}$ and anabolic steroids ${ }^{30}$ have been shown to improve postoperative nitrogen economy, but it is not known whether the effects of these hormones entail changes in liver function.

Somatostatin blocks pancreatic release of glucagon and insulin. ${ }^{31}$ The postoperative time course of glucagon was not measured in the control group, but has been shown to increase 12-24 hours after surgery. ${ }^{1232} 33$ Infusion of somatostatin returned to normal the expected increases of glucagon. Also insulin decreased postoperatively during the blockade. If anything, however, insulin decreases the capacity for urea synthesis in rats, ${ }^{34}$ and seems to have no effect on hepatic nitrogen conversion in humans. ${ }^{35}$ Apart from these changes, cortisol increases within hours after induction of anaesthesia, and may stay increased for up to one week after surgery depending on the severity of the stress induced. ${ }^{2} 3637$ Somatostatin did not influence the increase of cortisol during 12 hours postoperatively, but returned to normal the increase seen in the control group 24 hours postoperatively. The return to normal values of the increase in hepatic nitrogen conversion by somatostatin may therefore be caused by changes in both glucagon and cortisol. As the time course of the effect of somatostatin on the two hormones are different, this might show that both the preceding hormonal milieu and the actual hormonal concentrations during the investigation may be of importance. In perfused rat livers the catabolic hormones only increase the hepatic conversion of amino-nitrogen in livers from previously (three hours) operated rats, ${ }^{28}$ showing that these changes depend more on the preceding hormonal milieu shortly after surgery than on the actual concentration during the investigation.

In an earlier study, we prevented the catabolic response to upper abdominal surgery in humans by combined hormonalneural blockade, ameliorating the postoperative increases of glucagon, cortisol, catecholamines, and afferent responses from the wound. ${ }^{12}$ The blockade with somatostatin alone resulted in the same normalisation of the postoperative hepatic amino-nitrogen conversion, suggesting that glucagon directly or indirectly is of importance for the postoperative increase in hepatic amino acid conversion.
Triple infusion, however, of the traditional catabolic hormones (glucagon, cortisol, and catecholamines) to healthy humans only elicits a catabolism that is much less severe than in postoperative situations, ${ }^{3-5}$ suggesting that other factors are also important. Cytokines (tumour necrosis factor, interleukin 1 and 6) are among the prime candidates. Infusion of these cytokines, as just one of numerous other effects, reproduces the increased concentrations of both glucagon and cortisol as measured after surgery. ${ }^{27-29}$ This suggests that the cytokines either initiate or comediate the postoperative change in nitrogen homeostasis by changes in the traditional catabolic hormones. The effect of somatostatin infusion on the cytokine response is not known but the blockade may modify hormonal changes secondary to cytokine stimulation. Somatostatin also inhibits the release of several gastrointestinal peptides such as gastrin, secretin, cholecystokinin, vasoactive intestinal peptide, and pancreatic polypeptide. ${ }^{38} 39$ However, any influenze of these hormones on urea synthesis has never been shown. Furthermore, somatostatin reduces hepatic blood flow by $12-25 \%,{ }^{4041}$ which may contribute to down regulate hepatic aminonitrogen conversion, but such changes cannot account for the total effect of somatostatin.

The increased urea synthesis shows that the decrease in amino-nitrogen concentration after surgery was mainly the result of removal by the liver. This is primarily caused by decreases of the gluconeogenic amino acids alanine, arginine, glutamate, glycine, proline, serine, and the two essential amino acids lysine and threonine. ${ }^{12}$

The slight postoperative hyperglycaemia is caused by increased gluconeogensis ${ }^{42}$ and peripheral insulin resistance ${ }^{43}$ and was not affected by the blockade. Glucose suppresses urea synthesis mainly by decreasing glucagon, ${ }^{44}$ and spares some nitrogen postoperatively ${ }^{45}$, but the effect is limited by the insulin resistance. ${ }^{42}$ The normalisation of the hepatic amino-nitrogen conversion during the blockade and the relative hypoinsulinaemia is, therefore, not explained by the hyperglycaemia.

In conclusion, our study shows that the negative changes in postoperative nitrogen homeostasis resulting from increased hepatic efficacy for urea synthesis are preventable by somatostatin infusion. This suggests glucagon as a mediator. The exact mechanism of the inhibition remains uncertain, however, because of the multiple effects of the somatostatin infusion. A possible clinically beneficial effect of somatostatin in this situation awaits further studies.

The conscientious and skilful technical assistance of B Krog, $\mathrm{K}$ Prisholm, and L Hansen is gratefully acknowledged. Our thanks are due to Kabi-Pfrimmer, Erlangen, Germany, for providing the amino acid infusates, to Novo, Denmark, who supplied iodinated insulin, glucagon, and antisera, and to DuraScan Medical Products, Denmark for providing natural somatostatin at reduced prices.

This work was supported by grants from The Danish Medical Research Council (12-8168 and 12-8274) and The Danish Hospital Foundation for Medical Research, Region of Hospital Foundation for Medical Research, Region
Copenhagen, The Faeroe Islands, and Greenland (30/88). 
1 Heindorff $\mathrm{H}$, Vilstrup $\mathrm{H}$, Bucher D, Billesbølle $\mathrm{P}$, Thygesen $V$. Increased hepatic amino nitrogen conversion after elective cholecystectomy in man. Clin Sci 1988; 74: 539-45.

2 Heindorff $\mathrm{H}$, Harvald T, Nielsen J, Dalsgaard S, Almdal T, Vilstrup H. Cholecystectomy doubles the hepatic clearance of amino-N for two weeks. Clin Nutr 1990; 10: 10-7.

3 Gelfand RA, Matthews Bier DM, Sherwin RS. Role of counterregulatory hormones in the catabolic response to counterregulatory hormones in the cat

4 Bessey PQ, Brooks DC, Black PR, Aoki TT, Wilmore DW. Combined hormonal infusion simulates the metabolic response to injury. Ann Surg 1984; 200: 264-80.

5 Watters JM, Bessey PQ, Dinarello CA, Wolff SM, Wilmore DW. Both inflammatory and endocrine mediators stimulate host response to sepsis. Arch Surg 1986; 121: 179-90.

6 Kehlet $\mathrm{H}$. Surgical stress, the role of pain and analgesia. Br f Anaesth 1989; 63: 189-95.

7 Douglas RG, Humberstone DA, Haystead A, Shaw JHF. Metabolic effects of recombinant human growth hormone: isotopic studies in the post-absorptive state and during total parenteral nutrition. Br ₹ Surg 1990; 77: 785-90.

8 Asoh T, Shirasaka C, Ucrida I, Tsuji H. Effects of indomethacin on endocrine response and nitrogen loss indomethacin on endocrine response and

9 Vilstrup H, Hansen BA, Almdal T. Glucagon increase hepatic efficacy of urea synthesis. F Hepatol 1990;10: 46-50

10 Wolfe BM, Culebras JM, Aoki TT, O’Connor NE, Finley RJ, Kaczowka A, et al. The effects of glucagon on protein metabolism in normal man. Surgery 1979; 86: 248-57.

11 Sigsgaard I, Almdal T, Hansen BA, Vilstrup $H$. Dexamethasone increases the capacity of urea synthesis time dependently and reduces the body weight of rats. Liver 1988; 8: 193-7.

12 Heindorff $\mathrm{H}$, Schulze $\mathrm{S}$, Mogensen T, Almdal T, Kehlet $\mathrm{H}$, Vilstrup $\mathrm{H}$. Hormonal and neural blockade prevents the postoperative increase in amino acid clearance and urea synthesis. Surgery 1992; 111: 543-50.

13 Goodwin JF. Spectrophotometric quantization of plasma and urinary amino nitrogen with fluorodinitrobenzen Standard Methods in Clinical Chemistry 1970; 6: 89-98.

14 Fawcett JK, Scott JE. A rapid and precise method for the determination of urea. $\mathcal{F}$ Clin Pathol 1960; 13: 156-9.

15 Bergmeyer HU, Bernt E, Schmidt F, Stork H. D-glucose. Bestimmung mit hexokinase und glucose-6-phosphatdehydrogenase. IN: Metoden der enzymatischen analyse. Weinheim Bergstr: Verlag Chemie, 1970: 1163-72.

16 Heding L. Determination of total insulin (IRI) in insulin treated diabetic patients. Diabetologia 1972; 8: 260-8.

17 Heding L. Radioimmunological defemination of pancreatic and gut glucagon in plasma. Diabetologia 1971; 7: 10-9.

18 Langhoff $\mathrm{E}$, Flachs $\mathrm{H}$, Ladefoged J, Hvidberg EF Intraindividual consistency of prednisolone kinetics during longterm prednisone treatment. $\mathcal{f}$ Clin Pharm 1984; 26: 651-3.

19 Doessing M, Poulsen HE, Andreasen PB, Tygstrup N. A simple method for determination of antipyrine clearance. Clin Pharmacol Ther 1982; 26: 651-3.

20 Hansen BA, Vilstrup H. A method for determination of the capacity of urea synthesis in the rat. Scand $\mathcal{f}$ Clin Lab Invest $1985 ; 45: 315-20$.

21 Marco J, Calle C, Roman D, Diaz-Fierros M, Villanueva ML, Valverde I. Hyperglucagonism induced by gluco$\mathrm{ML}$, Valverde I. Hyperglucagonism induced by glucocorticoid

22 Heindorff $\mathrm{H}$, Almdal T, Vilstrup $\mathrm{H}$. Effects of epinephrine on urea synthesis in rats. Horm Metab Res 1991 (in press)

23 Goeschke H, Baer E, Girard J, Leutennegger A, Niedere W, Oberholzer M, Wolff G. Glucagon, insulin, cortisol, and growth hormone levels following major surgery: Their relationship to glucose and free fatty acid elevations. Horm Metab Res 1978; 10: 465-70.

24 Grunefeld J-P, Eloy L, Araujo A, Russo-Marie F. Effects of gluco- and glucocorticoids on renal and aortic gluco- and glucocorticoids on renal and aortic
prostaglandin synthesis. Am $\mathcal{f}$ Physiol 1986; 251: F810-6.
25 Reeds PJ, Palmer RM. Changes in prostaglandin release associated with inhibition of muscle protein synthesis by dexamethazone. Biochem f 1984; 219: 953-7.

26 Heindorff $\mathrm{H}$, Almdal T, Tygstrup N, Vilstrup $\mathrm{H}$. Effect of surgical stress and 'stress hormones' on urea synthesis in perfused rat livers. Surg Res Commun 1993; 14: 71-8.

27 Fong Y, Moldawer LL, Shires GT, Lowry SF. The biological characteristics of cytokines and their implications in surgical injury. Surg Gynecol Obstet 1990; 170: in surgical

28 Evans RE, Argiles JM, Williams DH. Metabolic effects of tumour necrosis factor and interleukin-1. Clin Sci 1989; 77: 357-64

29 Mealy K, van Lanschot JJB, Robinson BG, Rounds J, Wilmore DW. Are the catabolic effects of tumour necrosis factor mediated by glucocorticoids? Arch Surg 1990; 125: $42-8$.

30 Hausmann DF, Nutz V, Rommelsheim K, Caspari R, Mosebach KO. Anabolic steroids in polytrauma patients. Influence on renal nitrogen and amino acid losses: a double-blind study. FPEN 1990; 14: 111-4.

31 Adrian TE Barnes AI Long RG, O'Shaughnessey, Brown MR, Rivier J, et al. The effect of somatostatin analogs on secretion of growth, pancreatic, and gastrointestina hormones in man. $\mathcal{F}$ Clin Endocrinol Metab 1981; 53: 675-81

32 Mequid MM, Brennan MF, Aoki TT, Muller WA, Bal MR, Moore FD. Hormone-substrate interrelationship following trauma. Arch Surg 1974; 109: 776-83.

33 Goeschke H, Baer E, Girad J, Leutenegger A, Niederer W, Oberholzer M, et al. Glucagon, insulin, cortisol, and growth hormone levels following major surgery: their relationship to glucose and free fatty acid elevations. Horm Metab Res 1978; 10: 465-70.

34 Hansen BA, Krog B, Vilstrup H. Insulin and glucose decreases the capacity of urea synthesis in the rat. Scand $\mathcal{f}$ decreases the capacity of urea synth

35 Hamberg O, Vilstrup H. Effects of insulin and glucose on urea synthesis in normal man independent of pancreatic hormonal secretion. Clin Nutr (in press).

36 Rutberg H, Håkanson E, Anderberg B, Jorfeldt L, Smidt B Tegler L. Thyroid hormones, cathecholamines, and cortisol concentrations after upper abdominal surgery. Acta Chir Scand 1984; 150: 273-8.

37 Barton RN, Passingham BJ. Effect of binding to plasma proteins on the interpretation of plasma cortisol concentration after accidental injury. Clin Sci 1981; 61. 393-405.

38 Lin TM, Evans DC, Shaar J, Roth MA. Action of somatostatin on stomach, pancreas, gastric mucosal blood flow, and hormones. Am 7 Physiol 1983; 244: G40-5.

39 Fuessl HS, Barrin JM, Williams G, Adrian TE, Bloom SR. The effect of a long acting somatostatin analogue (SMS 201-945) on intermediary metabolism and gut hormones after a test meal in normal subjects. Aliment Pharmacol Therap 1987; 1: 321-30.

40 Merkel C, Gotta A, Caregaro L, Sacerdoti D, Rondana M, Roul A. Effect of somatostatin on liver blood flow and liver metabolic activity in patients

41 Clin Lab Invest 1987; 47: 667-72. somatostatin analoque on splanchnic haemodynamics and metabolism in healthy subjects and patients with liver cirrhosis. Scand $尹$ Gastroenterol 1986; (suppl 119): liver ci

42 Fulks RM, Li JB, Goldberg AL. Effects of insulin, glucose, and amino acids on protein turnover in rat diaphragm. f Biol Chem 1984; 74: 2238-48.

43 Nordenstrøm J, Sonnenfeld T, Arner P. Characterization of insulin resistance after surgery. Surgery 1989; 105: 28-35.

44 Vilstrup $H$. Effect of glucose on alanine derived urea synthesis. Clin Physiol 1984; 4: 495-507.

45 Radcliffe A, Johnson J, Dudley HAF. The effect of differen caloric doses of carbohydrate on nitrogen excretion after surgery. Br $\mathcal{F}$ Surg 1980; 67: 462-3. 